Available online on 15.06.2020 at http://jddtonline.info
Open Access to Pharmaceutical and Medical Research
unrestricted non-commercial use, provided the original work is properly cited

Open $\odot$ Access

Research Article

\title{
Total Phenolic Contents and Antioxidant Properties of Algerian Arbutus unedo L. Extracts
}

\author{
Saliha Laouicha a *, Abderrahmane Senator a,b, Abdallah Kherbache a,c and Hamama Bouriche a \\ a Laboratory of Applied Biochemistry, Faculty of Natural and Life Sciences, University Ferhat Abbas, Setif 1, Setif, 19000, Algeria \\ b Faculty of Natural and Life Sciences, University of Batna 2, Batna, 5000, Algeria \\ c Department of Microbiology and Biochemistry, Faculty of Sciences, University Mohamed Boudiaf, M’sila, M'sila, 28000, Algeria
}

\begin{abstract}
Arbutus unedo L. is a plant widely distributed in the Mediterranean basin and North Africa, frequently used in traditional folk medicine to treat diabetes and arterial hypertension. This study aims to evaluate the phenolic composition and antioxidant activity of ethyl acetate (EA.E) and $n$ butanolic (But.E) extracts prepared from leaves of Arbutus unedo. Total phenolic and flavonoids contents were determined

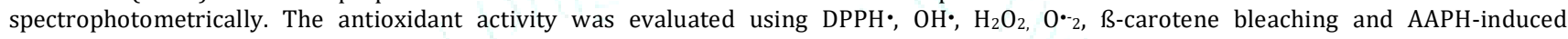
erythrocyte oxidative hemolysis assays. The phytochemical analysis showed the presence of polyphenols and flavonoids in both extracts. The high amount was observed in EA.E which exerted the stronger antioxidant effect, with $\mathrm{IC}_{50} \mathrm{values}$ of $3.43 \mu \mathrm{g} / \mathrm{mL}, 323.45 \mu \mathrm{g} / \mathrm{mL}, 38.40 \mu \mathrm{g} / \mathrm{mL}$ and $11.56 \mu \mathrm{g} / \mathrm{mL}$, in DPPH $, \mathrm{OH}^{\bullet}, \mathrm{O}_{-2}$ and $\mathrm{H}_{2} \mathrm{O}_{2}$ tests, respectively. Both extracts inhibited $\beta$-carotene bleaching, but EA.E is always more potent $(92 \%)$ than But.E (85\%). Furthermore, the EA.E showed the highest protective effect on erythrocyte hemolysis induced by AAPH, with half time hemolysis $\left(\mathrm{HT}_{50}\right.$ ) of $122.02 \mathrm{~min}$ at $40 \mu \mathrm{g} / \mathrm{mL}$. Taken together, this study showed that Arbutus unedo leaf extracts possess strong antioxidant potential, which may be attributed to the presence of a high amount of polyphenolic constituents. So, this plant might be exploited as a potential source of natural antioxidant agents for pharmaceutical and food applications.
\end{abstract}

Keywords: oxidative stress, antioxidant, phenolic compounds, Arbutus unedo.

Article Info: Received 28 March 2020; Review Completed 21 May 2020; Accepted 08 June 2020; Available online 15 June 2020

\section{Cite this article as:}

Laouicha S, Senator A, Kherbache A, Bouriche H, Total Phenolic Contents and Antioxidant Properties of Algerian Arbutus unedo L. Extracts, Journal of Drug Delivery and Therapeutics. 2020; 10(3-s):159-168

http://dx.doi.org/10.22270/jddt.v10i3-s.4182

*Address for Correspondence:

Saliha Laouicha, Laboratory of Applied Biochemistry, Faculty of Natural and Life Sciences, University Ferhat Abbas, Setif 1, Setif, 19000, Algeria

\section{INTRODUCTION}

Endogenous metabolic processes in the human body might produce strongly different forms of reactive oxygen species (ROS). These species can be free radicals such as superoxide anion, hydroxyl radicals and non-radical species such as hydrogen peroxide, singlet oxygen 1 . Lipids, DNA and proteins are the major targets of ROS in the body ${ }^{2}$. The oxidative stress caused by the excess of uncontrolled ROS is involved in several pathological situations including hypertension, hypercholesterolemia, diabetes, heart failure 3 , atherosclerosis, ischemia-reperfusion, alzheimer's disease, rheumatic arthritis, cancer, aging process ${ }^{1}$, immunological and chronic inflammation disorders ${ }^{4}$.

Currently, many studies are focused on searching for medicinal plants with anti-antioxidant activities and their active principles in order to find new therapeutic agents. These natural products have little severe side effects at low cost. The use of natural antioxidants present in medicinal and dietary plants such as polyphenols has gained enormous importance. Polyphenols possess ideal structural chemistry for free radical scavenging activity ${ }^{5}$. Antioxidant properties of polyphenols arise from their high reactivity as hydrogen or electron donors, and from the ability of the polyphenol derived radical to stabilize and delocalize the unpaired electron (chain-breaking function), and from their ability to chelate transition metal ions and then inducing the termination of the Fenton reaction ${ }^{6}$.

Arbutus unedo L. (Ericaceae) is widely distributed in the Mediterranean basin and North Africa, as well as in other regions with hot summers and mild rainy winters ${ }^{7}$. This plant is frequently used in traditional folk medicine as a natural remedy for diabetes and arterial hypertension. The leaves of Arbutus unedo (A. unedo) are used as a urinary antiseptic, antidiarrheal, astringent, depurative, against blenorrhagia 8 . In Turkey, the tea prepared from leaves is used as a diuretic 9 . The fruits of $A$. unedo are consumed 
mainly as a processed product but maybe a good source of antioxidants if consumed as fresh fruit. Processed products include alcoholic beverages such as cider and an increasingly popular industrially produced aromatic distillate. Other nonalcoholic strawberry tree products are jams, marmalades and jellies ${ }^{10}$.

Due to the ethnobotanical importance of $A$. unedo and the fewer studies that prove their antioxidant activity, this study was conducted to show the total phenolic content and to assess the potential antioxidant capacity of the ethyl acetate and $n$-butanolic extracts of this plant.

\section{MATERIALS AND METHODS}

\subsection{Plant material}

Arbutus unedo leaves were collected in June 2017 from Setif region (Algeria). The plant was identified and authenticated taxonomically by Pr. Laouar Hocine (Faculty of Natural and Life Sciences, University of Setif 1, Algeria). A voucher specimen (AU 06/17) is deposited in the herbarium of the same faculty.

\subsection{Extraction}

The aerial part of $A$. unedo was cleaned, shadow dried and pulverized to dry powder. Ethyl acetate and $n$-butanolic extracts were prepared according 11 . A sample of $100 \mathrm{~g}$ was treated three times with $70 \%$ methanol. The filtered methanol extract was evaporated to dryness and the residue was dissolved in boiling water and kept $24 \mathrm{~h}$ at room temperature. After filtration, the aqueous solution was treated with ethyl acetate and $n$-butanol successively, and then their extracts were concentrated to dryness (yields: $4 \%$ and $7.5 \%$, respectively). Both extracts were then stored at $32^{\circ} \mathrm{C}$ until use.

\subsection{Animals}

Swiss Albinos mice (25-30 g) of either sex were purchased from Pasteur Institute of Algiers (Algeria). All animals were kept to acclimatize under the laboratory conditions for one week and had free access to a standard commercial diet and water ad libitum. All procedures were performed following European Union Guidelines for Animals Experimentation (2007/526/EC).

\subsection{Determination of total phenolic content}

Total phenolic content was determined by the FolinCiocalteu method 12 . Briefly, $100 \mu \mathrm{L}$ of each extract $(1$ $\mathrm{mg} / \mathrm{mL}$ ) or gallic acid (used as standard) was mixed with $500 \mu \mathrm{L}$ of Folin-Ciocalteu reagent for $4 \mathrm{~min}$. Then, $400 \mu \mathrm{L}$ of sodium carbonate (7.5\%) was added. After incubation for 90 min at room temperature, the absorbance was measured at $765 \mathrm{~nm}$. All tests were performed in triplicate, and the concentration of total phenolic compounds was expressed as $\mu \mathrm{g}$ of gallic acid equivalent per mg of extract ( $\mu \mathrm{g} \mathrm{GAE} / \mathrm{mg}$ extract).

\subsection{Determination of total flavonoid content}

Total flavonoid content was evaluated by a colorimetric method based on the formation of a flavonoid-aluminum complex ${ }^{13}$. A volume of $1 \mathrm{~mL}$ of $\mathrm{AlCl}_{3}$ (2\% in ethanol) was added to $1 \mathrm{~mL}$ of each extract or quercetin at different concentrations. After 20 min of incubation, the absorbance was measured at $430 \mathrm{~nm}$, and the total flavonoïd concentration was expressed as $\mu \mathrm{g}$ quercetin equivalent per $\mathrm{mg}$ of extract ( $\mu \mathrm{g} \mathrm{QE} / \mathrm{mg}$ extract).

\subsection{Antioxidant activities}

\subsubsection{DPPH radical scavenging assay}

The free radical scavenging activity of samples was measured ${ }^{14}$. To $2 \mathrm{~mL}$ of ethanolic solution of $\mathrm{DPPH} \cdot(0.1$ $\mathrm{mM}), 2 \mathrm{~mL}$ of the extracts dissolved in ethanol was added to obtain different concentrations $(100-500 \mu \mathrm{g} / \mathrm{mL})$. An equal volume ( $2 \mathrm{~mL}$ ) of ethanol was added to the control without the test sample. Butylated Hydroxytoluene (BHT) was used as a reference. After $30 \mathrm{~min}$, the decrease in the absorbance of the test mixture was recorded at $517 \mathrm{~nm}$, and the inhibition percentage was calculated as follows: Inhibition $(\%)=[($ Absorbance of control- Absorbance of the sample $) /$ Absorbance of control] X 100.

\subsection{2. $\quad \mathrm{OH} \cdot \mathrm{scavenging}$ activity}

The hydroxyl radical scavenging activity of extracts was assayed ${ }^{15}$. Briefly, $0.5 \mathrm{~mL}$ of $\mathrm{FeSO}_{4}(1.5 \mathrm{mM})$ and $0.35 \mathrm{~mL}$ of hydrogen peroxide $(6 \mathrm{mM})$ were mixed with $0.1 \mathrm{~mL}$ of extracts or vitamin $\mathrm{C}$, used as reference, at varied concentrations $(100-1400 \mu \mathrm{g} / \mathrm{mL})$. Then, $0.15 \mathrm{~mL}$ of sodium salicylate $(20 \mathrm{mM})$ was added. After incubation for $20 \mathrm{~min}$ at $37^{\circ} \mathrm{C}$, the absorbance was measured at $562 \mathrm{~nm}$. The hydroxyl radical scavenging activity was calculated as follow: Hydroxyl radical scavenging activity $(\%)=[1$ $\left.\left(A_{1}-A_{2}\right) / A_{0}\right] \times 100$, where $A_{0}$ : mean absorbance without extract, $A_{1}$ : mean absorbance in the presence of the extract, $\mathrm{A}_{2}$ : mean absorbance without sodium salicylate.

\subsection{3. $\mathrm{H}_{2} \mathrm{O}_{2}$ scavenging activity}

The ability of the extracts to scavenge hydrogen peroxide was determined 16 . Briefly, $20 \mu \mathrm{L}$ of each extract or ascorbic acid (standard) at different concentrations $(10-200 \mu \mathrm{g} / \mathrm{mL})$ was mixed with $100 \mu \mathrm{L}$ of phosphate buffer $(0.1 \mathrm{M}, \mathrm{pH}$ ) and $20 \mu \mathrm{L}$ of hydrogen peroxide solution $(10 \mathrm{mM})$ and incubated $5 \mathrm{~min}$ at $37^{\circ} \mathrm{C}$. Then, $30 \mu \mathrm{L}$ of ABTS $(1.25 \mathrm{mM})$ and $30 \mu \mathrm{L}$ of peroxidase $(1 \mathrm{U} / \mathrm{ml})$ were added, and the reaction mixture was incubated $10 \mathrm{~min}$ at $37^{\circ} \mathrm{C}$. The absorbance was measured at $405 \mathrm{~nm}$ using a 96-well microplate reader (ELX 800 de Bio-TEK instruments). The ability of extracts to scavenge the hydrogen peroxide was calculated according to the following equation: Hydrogen peroxide scavenging activity $(\%)=[(\mathrm{Ac}-\mathrm{As}) / \mathrm{Ac}] \times 100$, where Ac is the absorbance of the control and As is the absorbance in the presence of extracts or standard.

\subsection{4. $\quad 0 \bullet_{2}$ scavenging activity}

The capacity of $A$. unedo extracts to scavenge superoxide anion radicals was measured 5 . Superoxide radicals are generated in the mixture containing $500 \mu \mathrm{L}$ NBT $(156 \mu \mathrm{M}$ in $0.1 \mathrm{M}$ phosphate buffer, $\mathrm{pH} 7.4), 500 \mu \mathrm{L}$ NADH $(468 \mu \mathrm{M}$ NADH in $0.1 \mathrm{M}$ phosphate buffer, $\mathrm{pH} 7.4$ ) and $50 \mu \mathrm{L}$ of each extract or gallic acid (standard) at different concentrations $(5-500 \mu \mathrm{g} / \mathrm{mL})$. The reaction was initiated by adding $50 \mu \mathrm{L}$ of PMS $(60 \mu \mathrm{M}$ in $0.1 \mathrm{M}$ phosphate buffer, $\mathrm{pH} 7.4)$ to the mixture. After $5 \mathrm{~min}$ of incubation at $25^{\circ} \mathrm{C}$, the absorbance was measured at $560 \mathrm{~nm}$ against a blank (without PMS). Decreased absorbance of the reaction mixture indicates the increase of superoxide anion scavenging activity. The superoxide anion scavenging activity was calculated using the following equation: Superoxide anion scavenging activity $(\%)=[(\mathrm{Ac}-\mathrm{As}) / \mathrm{Ac}] \times 100$, where Ac is the absorbance of the control and As is the absorbance in the presence of extracts or standard.

\subsubsection{Reducing power}

The reducing power of the extracts was determined ${ }^{17}$. In this method, antioxidant compounds present in the extracts from a colored complex with potassium ferricyanide, 
trichloroacetic acid and ferric chloride, which was measured at $700 \mathrm{~nm}$. The increase in absorbance of the reaction mixture indicates the reducing power of the samples. Different concentrations $(20-100 \mu \mathrm{g} / \mathrm{mL})$ of extracts or BHT (reference) were mixed with $2.5 \mathrm{~mL}$ of phosphate buffer $(0.2$ $\mathrm{M}, \mathrm{pH} 6.6)$ and $2.5 \mathrm{~mL}$ of potassium ferrocyanide $(1 \%)$ and incubated at $50^{\circ} \mathrm{C}$ for $20 \mathrm{~min}$. A volume of $2.5 \mathrm{~mL}$ of trichloroacetic acid (10\%) was added to the mixture and then centrifuged at $800 \mathrm{rpm}$ for $10 \mathrm{~min}$. After that, the upper layer of the solution $(2.5 \mathrm{~mL})$ was mixed with $2.5 \mathrm{~mL}$ of distilled water and $0.5 \mathrm{~mL}$ of $0.1 \%$ ferric chloride $\left(\mathrm{FeCl}_{3}\right)$ and the absorbance was measured at $700 \mathrm{~nm}$. Increased absorbance of the reaction mixture indicates increased reducing power.

\subsubsection{B-carotene bleaching assay}

The ability of extracts to prevent $\beta$-carotene bleaching was determined 18. A fresh emulsion of $ß$-carotene/linoleic acid was prepared by dissolving $0.5 \mathrm{mg}$ of $\beta$-carotene, $25 \mathrm{~mL}$ of linoleic acid and $200 \mathrm{~mL}$ of Tween 40 in $1 \mathrm{~mL}$ of chloroform. The chloroform was completely evaporated under vacuum in a rotatory evaporator at $45^{\circ} \mathrm{C}$. Next, $100 \mathrm{~mL}$ of bi-distilled water was added, and the obtained mixture was vigorously stirred. Then, $2.5 \mathrm{~mL}$ of prepared emulsion were mixed with $0.5 \mathrm{~mL}$ of each extract $(2 \mathrm{mg} / \mathrm{mL})$ or BHT (standard). After incubation for $2 \mathrm{~h}$ at $50^{\circ} \mathrm{C}$, the absorbance was measured at $470 \mathrm{~nm}$. The antioxidant activity was calculated using the following equation:

Antioxidant activity \% $=[1-($ At0 - At120) test $/($ At0-At120 $)$ control] x 100, where At0 is the absorbance measured at time zero and At120 is absorbance measured after $2 \mathrm{~h}$.

\subsubsection{Anti-hemolytic activity}

The anti-hemolytic activity of the extracts was evaluated by the inhibition of 2,2,-azobis (2-amidinopropane) dihydrochloride (AAPH)-induced oxidative erythrocyte hemolysis ${ }^{19}$. Blood was obtained from mice and diluted to $1 \%$ with phosphate buffer saline (PBS, pH 7,4). A $120 \mu \mathrm{L}$ of erythrocyte suspension was mixed with $60 \mu \mathrm{L}$ of extracts $(40,20,10,5 \mu \mathrm{g} / \mathrm{ml}$ in PBS). The reaction was initiated by the addition of $120 \mu \mathrm{L}$ of AAPH $(120 \mathrm{mM})$, and the mixture was incubated at $37^{\circ} \mathrm{C}$, in order to induce free radical chain oxidation in the erythrocytes by generating aqueous peroxyl radicals by thermal decomposition of AAPH. The decrease of the absorbance was measured at $630 \mathrm{~nm}$ every $10 \mathrm{~min}$ for 4 $\mathrm{h}$ using a 96-well microplate reader (ELX 800 de Bio-TEK instruments). Trolox and PBS were used as a standard and negative control, respectively. The blood resistance to free radical attack is expressed by the time necessary to hemolyse $50 \%$ of the initial erythrocytes (half-hemolysis time, $\mathrm{HT}_{50}$ in min). A high $\mathrm{HT}_{50}$ corresponds to a good resistance of erythrocytes.

\section{Statistical analysis}

The obtained results were expressed as means \pm SD. The statistical analysis was performed using one way ANOVA followed by Tukey's multiple comparison tests. The differences were considered statistically significant at $\mathrm{p}<0.05$.

\section{RESULTS}

\subsection{Total phenols and flavonoids content}

The values of total phenolic and flavonoid contents of both extracts of A. unedo (Table 1) showed that ethyl acetate extract was the richest. It contains a high amount of total phenolic compounds, which were two folds higher than those found in the $n$-butanolic extract.

Table 1: Polyphenol and flavonoid content of ethyl acetate (EA.E) and $n$-butanolic (Burt.E) extracts of Arbutus unedo.

\begin{tabular}{|l|c|c|}
\hline Extract & Polyphenols ( $\mu$ g GAE/mg extract) & Flavonoids ( $\mu \mathrm{g}$ QE/mg extract) \\
\hline EA.E & $836.51 \pm 90.54$ & $53.99 \pm 5.33$ \\
\hline But.E & $559.33 \pm 68.74$ & $3.75 \pm 0.19$ \\
\hline
\end{tabular}

Values are mean of triplicate determination $(n=3) \pm S D$.

\subsection{Antioxidant activities}

\subsubsection{DPPH radical scavenging activity}

The free radical scavenging activity of $A$. unedo extracts was evaluated by measuring its capacity to scavenge the stable free radical formed in solution by donating a hydrogen atom or an electron. Results shown in figure 1 suggest that $A$. unedo exhibits a noticeable antiradical activity against free radical DPPH. Indeed, the ethyl acetate extract exerted a strong and concentration-dependent free radical scavenging activity with an $\mathrm{IC}_{50}=3.43 \mu \mathrm{g} / \mathrm{mL}$, which is better than that obtained with But.E $\left(\mathrm{IC}_{50}=13.77 \mu \mathrm{g} / \mathrm{ml}\right)$ and $\mathrm{BHT}\left(\mathrm{IC}_{50}=\right.$ $8.21 \mu \mathrm{g} / \mathrm{ml})$. These results are in agreement with Pabuçcuoğlu et al. 20, who demonstrated that the ethanol and methanol extract from the same plant leaf displayed potent antioxidant activity in ABTS free radical assay.

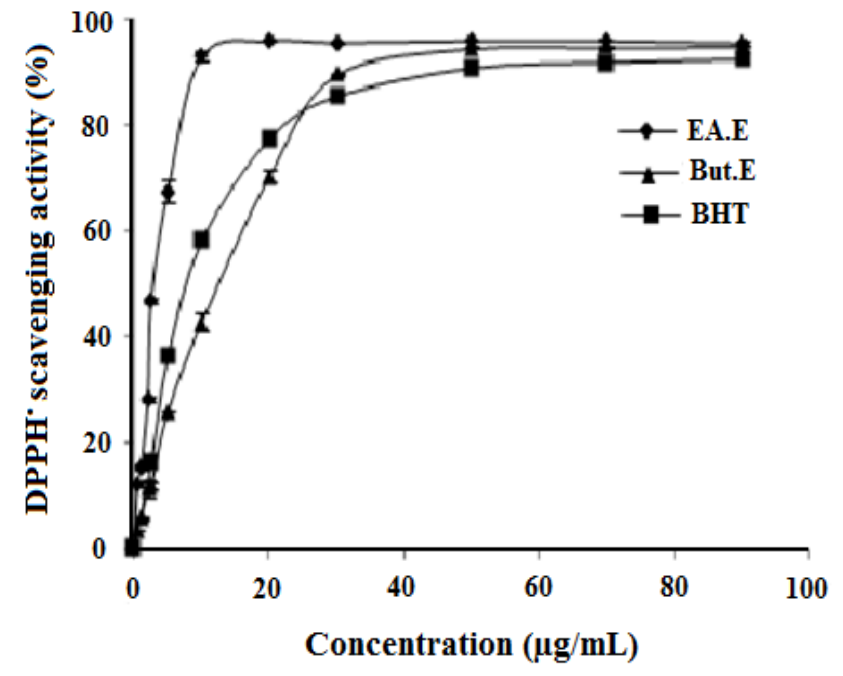

Figure 1: DPPH radical scavenging activity of ethyl acetate extract (EA.E), $n$-butanolic extract (But.E) of Arbutus unedo and BHT. Values are means \pm SD $(n=3)$. 


\subsection{2. $\quad \mathrm{OH} \cdot$ scavenging activity}

Hydroxyl radical is the most reactive free radical, which can induce severe oxidative damages to biomolecules 5,21 . It attacks proteins, DNA, the polyunsaturated fatty acid in membranes, and the most biological molecule it contacts 22 . It is known to be capable of abstracting hydrogen atoms from membrane lipids and leads to lipid peroxidation, which is a key process in many pathological conditions.
The obtained results suggest that $A$. unedo extracts are hydroxyl radical scavengers. This scavenging capacity may be due to their richness in phenolic compounds. Indeed, EA.E which is rich in this compounds exhibited the best effect (figure 2) with an $\mathrm{IC}_{50}=323.45 \mu \mathrm{g} / \mathrm{mL}$ compared with But.E $\left(\mathrm{IC}_{50}=611.19 \mu \mathrm{g} / \mathrm{mL}\right)$, but less important than ascorbic acid $\left(\mathrm{IC}_{50}=290 \mu \mathrm{g} / \mathrm{mL}\right)$.

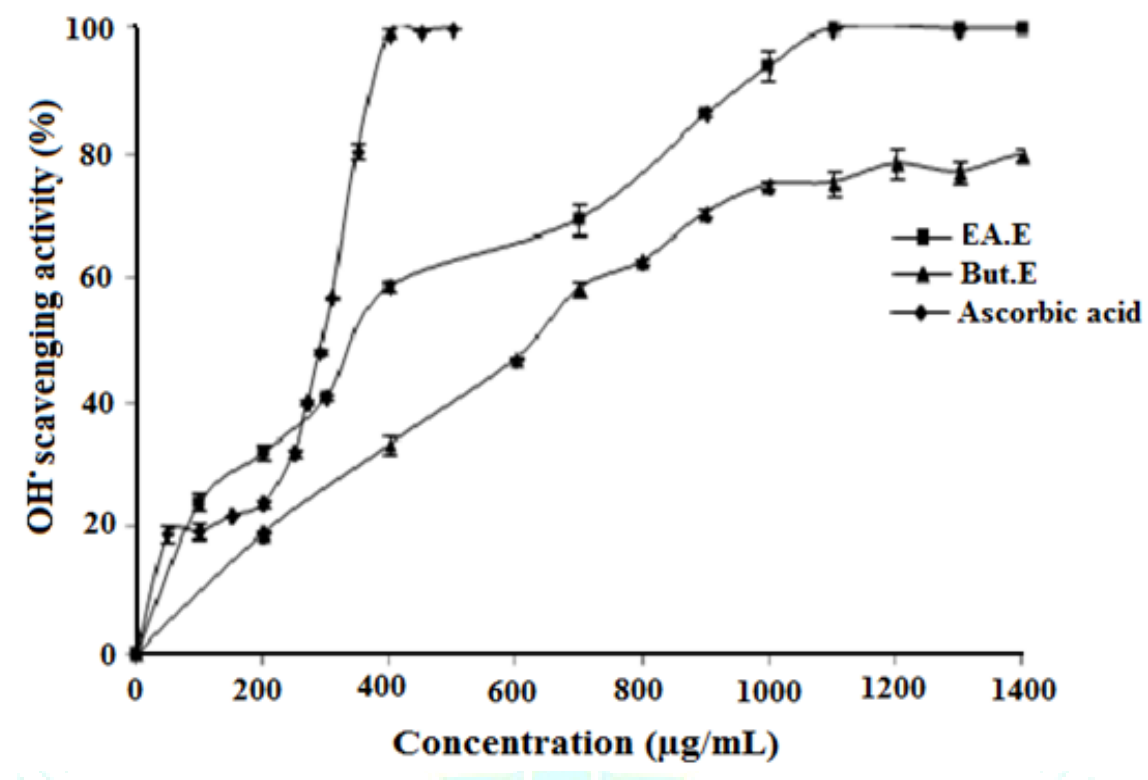

Figure 2: Hydroxyl radical scavenging activity of ethyl acetate extract (EA.E) and $n$-butanolic extract (But.E) of Arbutus unedo and ascorbic acid. Values are means $\pm \operatorname{SD}(n=3)$.

\subsection{3. $\mathrm{H}_{2} \mathrm{O}_{2}$ scavenging activity}

Hydrogen peroxide can be toxic to cells because it may cross the cell membranes rapidly and produces many reactive hydroxyl radicals by the Fenton reaction 23 with $\mathrm{Fe}^{2+}$, and possibly $\mathrm{Cu}^{2+}$ ions. Hydrogen peroxide can, therefore, inactivate a few enzymes directly by oxidation of essential thiol groups 22 .
As shown in figure 3, A. unedo extracts had a strong $\mathrm{H}_{2} \mathrm{O}_{2}$ scavenging ability when compared to ascorbic acid used as standard, and this effect was concentration-dependent. At the concentration of $100 \mu \mathrm{g} / \mathrm{mL}$, both extracts exerted the same percentage of $\mathrm{H}_{2} \mathrm{O}_{2}$ scavenging activity (98\%). This effect was better than that obtained with ascorbic acid $(87 \%)$.

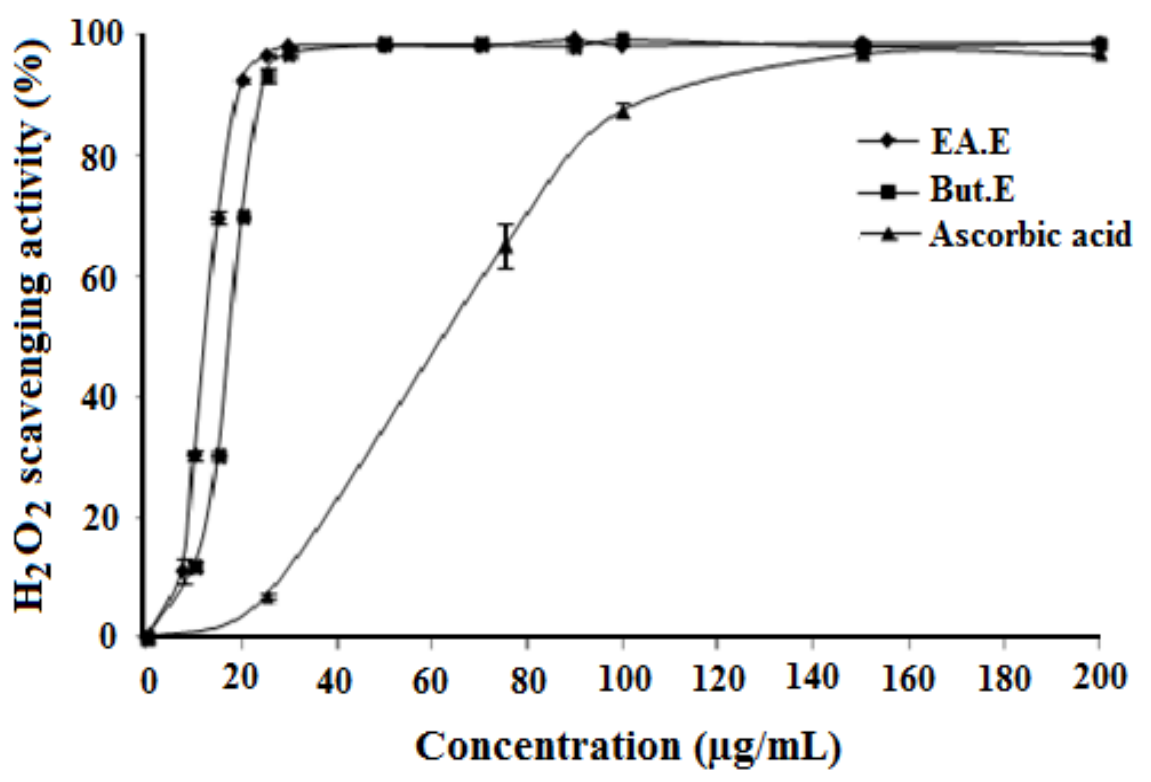

Figure 3: $\mathrm{H}_{2} \mathrm{O}_{2}$ scavenging activity of ethyl acetate extract (EA.E) and $n$-butanolic extract (But.E) of Arbutus unedo and ascorbic acid. Each value represents the means $\pm \operatorname{SD}(n=3)$. 


\subsection{4. $\quad 0 * 2$ radical scavenging activity}

It is well known that superoxide anions radicals are normally produced endogenously by several oxidative enzymes such as xanthine oxidase. In this study, superoxide anions radicals were derived in a non-enzymatic system (PMS-NADH-NBT) from dissolved oxygen by PMS-NADH coupling reaction reduces NBT 1,24 . These radicals can directly initiate lipid peroxidation and damage, thereby biomolecules 22 , and its effects may be magnified by producing more ROS contributing to tissue damage and various diseases 5 . The superoxide anion radical scavenging activity of $A$. unedo extracts, as shown in figure 4, is concentration-dependent. The ethyl acetate extract exhibited much higher activity ( $\mathrm{IC}_{50}=38.40 \mu \mathrm{g} / \mathrm{mL}$ ) than gallic acid ( $\mathrm{IC}_{50}=52.23 \mu \mathrm{g} / \mathrm{mL}$ ), used as reference and But.E which showed the smallest effect with an $\mathrm{IC}_{50}$ of 103.80 $\mu \mathrm{g} / \mathrm{mL}$. These differences are statistically significant $(\mathrm{p}<0.05)$. This capacity to scavenge superoxide anion may be attributed to the amount of phenolic compounds in the extracts, as ethyl acetate extract showed the best antioxidant activity.

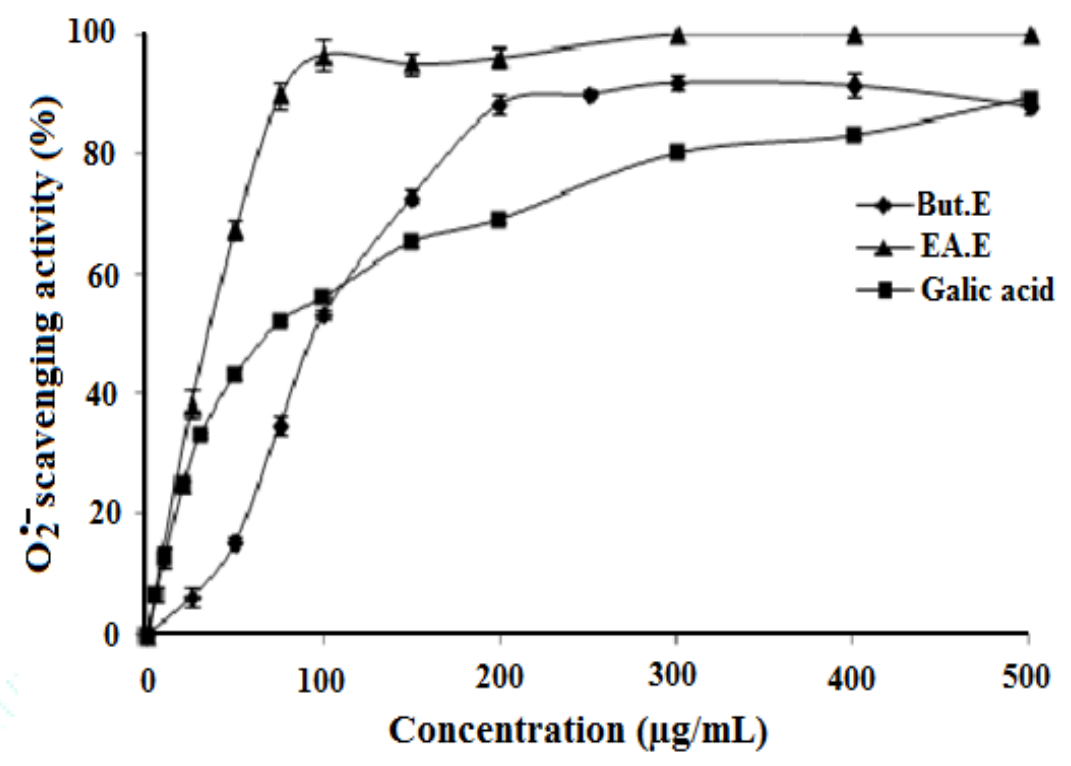

Figure 4: Anion superoxide radical scavenging activity of ethyl acetate extract (EA.E), $n$-butanolic extract (But.E) of Arbutus unedo and gallic acid. Values are means $\pm \operatorname{SD}(n=3)$.

\subsubsection{Total reducing capacity}

The reduction of ferrous ion $\left(\mathrm{Fe}^{3+}\right)$ to ferric ion $\left(\mathrm{Fe}^{2+}\right)$ is measured by the strength of the green-blue color of the solution, which absorbs at $700 \mathrm{~nm}{ }^{17}$. The obtained results suggest that both extracts exhibited a good concentrationdependent reducing power (figure 5). The EA.E exerted the stronger reducing power with $\mathrm{IC}_{50}=12.25 \mu \mathrm{g} / \mathrm{mL}$, followed by the But.E and BHT with $\mathrm{IC}_{50}$ of $21.47 \mu \mathrm{g} / \mathrm{mL}$ and 23.09 $\mu \mathrm{g} / \mathrm{mL}$, respectively.

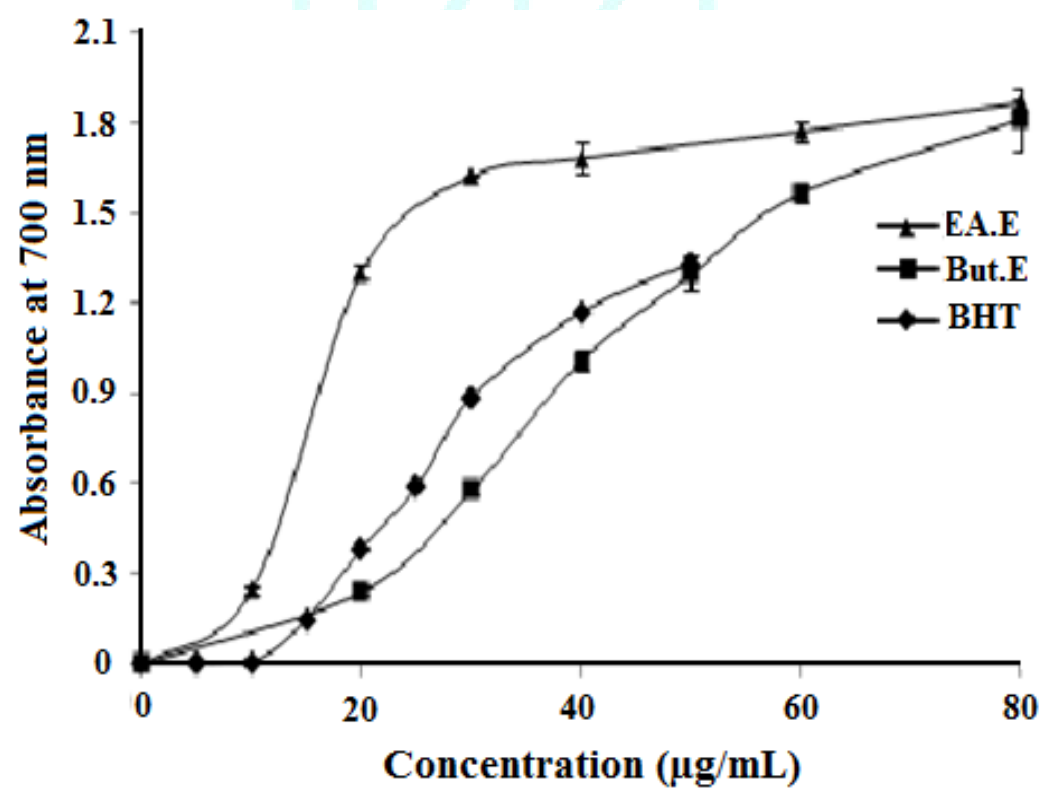

Figure 5: Reducing power of ethyl acetate extract (EA.E), $n$-butanolic extract (But.E) of Arbutus unedo and BHT. Values are means $\pm \operatorname{SD}(n=3)$. 


\subsubsection{B-Carotene bleaching}

Lipid peroxidation is a chain reaction initiated by the hydrogen abstraction or the addition of oxygen radicals, resulting in the oxidative damage of polyunsaturated fatty acids of biological membranes 25, producing thereby derivatives such as hydroperoxides and malonaldehyde that can be used to quantify the degree of damage in the cell. These derivatives play a crucial role in the pathogenesis of many diseases ${ }^{26}$. In this study, the ability of $A$. unedo to inhibit lipid peroxidation was tested by the $\beta$-carotene bleaching method. Linoleic acid acts in this assay as a free radical generator that produces peroxyl radicals (hydroperoxides) under thermally induced oxidation. Peroxyl radicals react with $\beta$-carotene and lead to its rapid discoloration ${ }^{27}$. The presence of antioxidants can hinder the extent of $\beta$-carotene bleaching by neutralizing the linoleatefree radical and other free radicals formed in the system 28 . The results of the present study (figure 6) indicated that both extracts had acted as an effective antioxidant in the $ß$ carotene linoleic acid model system. The absorbance in the presence of both extracts of $A$. unedo was very low and remained stable during the $120 \mathrm{~min}$ of incubation. The activity of the $n$-butanolic extract is less (85\%) than that obtained with EA.E, which showed the same effect (92\%) as the standard (BHT).

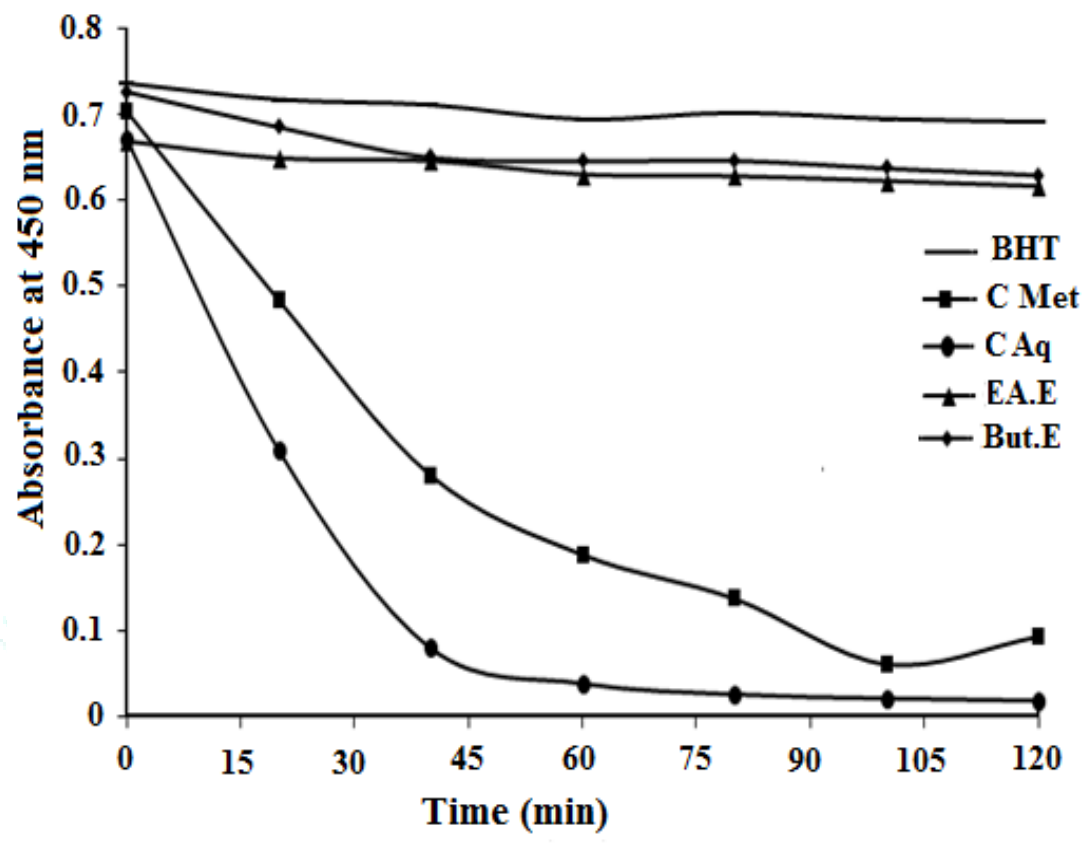

Figure 6: Kinetics of antioxidant activity of Arbutus unedo ethyl acetate extract (EA.E), $n$-butanolic extract (But.E) and BHT in a $ß$-carotene-linoleic acid system. C Met: methanolic control, C Aq: aqueous control. Values are expressed as means \pm SD ( $n=3$ ).

\subsubsection{Anti-hemolytic effect of Arbutus unedo extracts}

Results of the effect of $A$. unedo extracts and Trolox on erythrocyte hemolysis induced by AAPH were reported in figure 7 and table 2 . Both extracts exhibit a dose-dependent effect, and the highest protective effect was obtained with EA.E, which possessed an approximate effect to that exerted by Trolox. At $40 \mu \mathrm{g} / \mathrm{mL}$, the calculated half time hemolysis $\left(\mathrm{HT}_{50}\right)$ values are $122.02 \mathrm{~min}$ and $115.26 \mathrm{~min}$, respectively. These values are statistically more important than that obtained with But.E at the same dose $\left(\mathrm{HT}_{50}=73.48 \mathrm{~min}\right)$ and with the negative control (46.5 min).

Table 2: The antihemolytic activity of ethyl acetate (EA.E) and $n$-butanolic t (Burt.E) extracts of Arbutus unedo and Trolox.

\begin{tabular}{|l|l|l|l|l|}
\hline \multicolumn{5}{|c|}{ Hemolysis half-time (min) } \\
\hline Samples & $5 \mu \mathrm{g} / \mathrm{mL}$ & $10 \mu \mathrm{g} / \mathrm{mL}$ & $20 \mu \mathrm{g} / \mathrm{mL}$ & $40 \mu \mathrm{g} / \mathrm{mL}$ \\
\hline EA. E & $66.67 \pm 1.15^{* *}$ & $81.04 \pm 3.73^{* * *}$ & $109.42 \pm 2.03^{* * *}$ & $122.02 \pm 3.51^{* * *}$ \\
\hline But. E & $49.15 \pm 4.55 \mathrm{~ns}$ & $56.68 \pm 3.12^{* *}$ & $62.86 \pm 1.00^{* * *}$ & $73.48 \pm 2.63^{* * *}$ \\
\hline Trolox & $68.03 \pm 8.10^{* *}$ & $79.95 \pm 2.54^{* * *}$ & $92.59 \pm 4.87^{* * *}$ & $115.26 \pm 5.77^{* * *}$ \\
\hline Control & \multicolumn{4}{|c|}{$46.50 \pm 0.56$} \\
\hline
\end{tabular}

The values are means $\pm \mathrm{SD}(\mathrm{n}=3) .{ }^{* *} \mathrm{P}<0.01 ;{ }^{* * *} \mathrm{P}<0.001 ;$ ns: Not significant. 

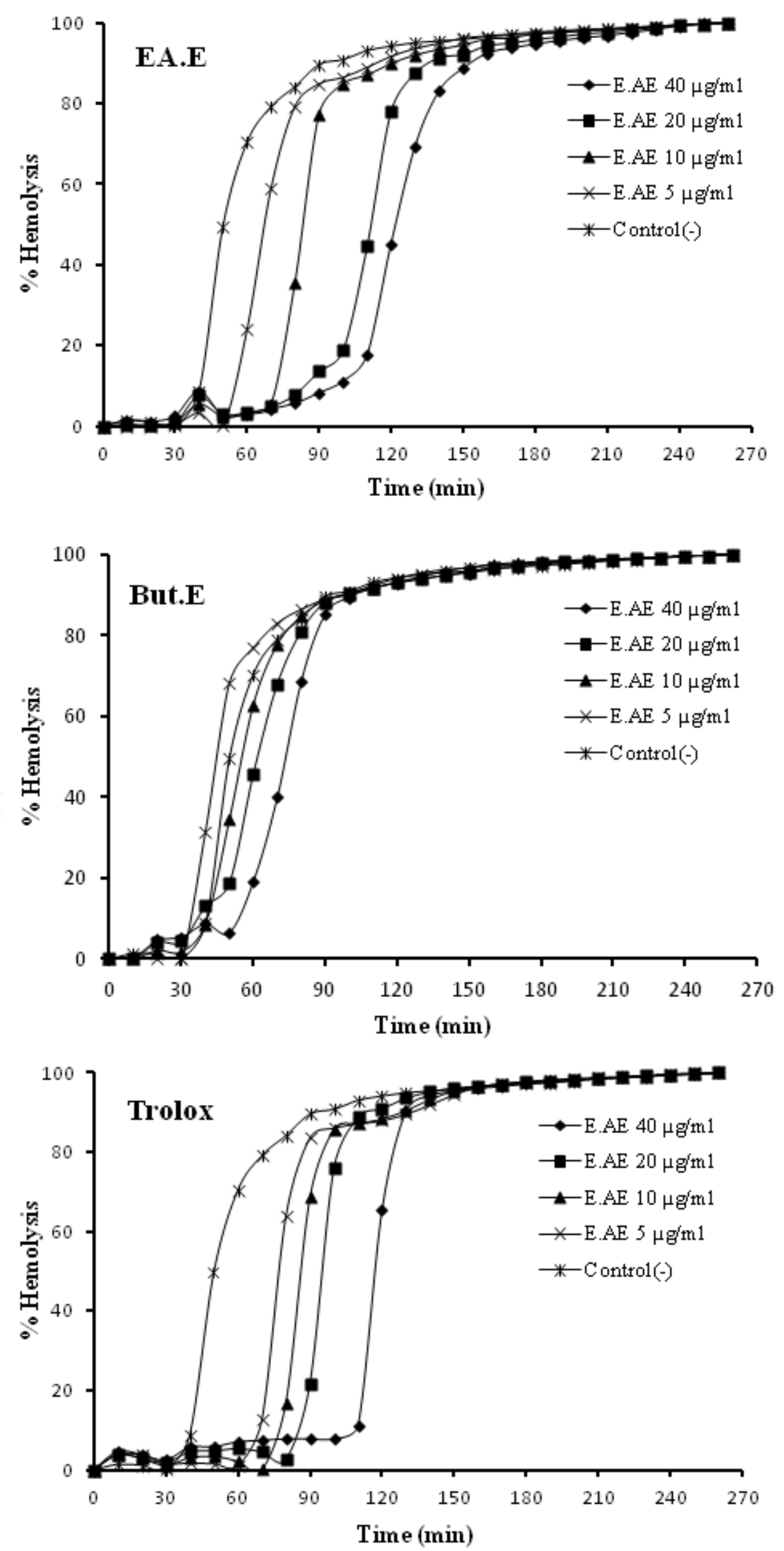

Figure 7: Protective effect of ethyl acetate extract (EA.E), $n$-butanolic extract (But.E) of Arbutus unedo and Trolox against AAPH induced erythrocyte hemolysis. The values are means $\pm \operatorname{SD}(n=3)$. 


\section{DISCUSSION}

Bioactive compounds from natural sources such as flavonoids and phenolic acids are well known for the prevention and/or treatment of various types of human diseases. There are close relationships and positive correlation between the phenolic content and antioxidant activity of plant extracts ${ }^{29}$. Several studies have focused on the biological activities of phenolic compounds and flavonoids, which are potential antioxidants agents 30 . These bioactive compounds can replace the synthetic antioxidants which are restricted for their side effects.

The ethyl acetate extract of $A$. unedo leaves was found to have a high quantity of polyphenols and flavonoids, and this could be due to different degrees of the polarity of the solvents used for the extraction of polyphenolic compounds. The content of flavonoids significantly differs from one plant sample to another, and this may be due to various factors, such as the type of soil, microclimatic conditions, geographic position, size, age and vegetational stage of plants and leaves ${ }^{31}$.

Antioxidants can exert their protecting effects by various mechanisms, as prevention of radical chain reactions of oxidation and they act by inhibiting the initiation and propagation steps leading to the termination of the reaction and delay the oxidation process ${ }^{30}$. They also act by binding of transition metal ion catalysts, decomposition of peroxides, prevention of continued hydrogen abstraction, reductive capacity and radical scavenging or preventing the generation of ROS; subsequently, they retard the progress of many chronic diseases 24 . The ethyl acetate extract was found to possess the strong radical scavenging activity against DPPH $\cdot$, $\mathrm{OH} \cdot \mathrm{H}_{2} \mathrm{O}_{2}$ and $\mathrm{O}_{-2}$ and these results are correlated well with phenolic content, evidencing its ability to have extracted a considerable amount of polyphenols and flavonoids which are responsible for antioxidant activities in many plants species ${ }^{30}$.

Flavonol glycosides and tannins might have been the active principles responsible for the antioxidant activity of $A$. unedo leaf 20 . The antioxidant activity of these compounds is mainly due to their redox properties, which can play an important role in absorbing and neutralizing free radicals by their hydrogen donating ability ${ }^{32}$, quenching singlet and triplet oxygen or decreasing peroxides 33. These polyphenols contain conjugated ring structures and hydroxyl groups, which can act as an antioxidant by scavenging free radicals, lipid peroxy radicals and stabilizing free radicals involved in these oxidative processes ${ }^{34}$. Moreover, it has been reported that the antioxidant activities of phenolic acids and their derivatives depend on the number of hydroxy groups in the molecules 35 .

The ferrous chelating capacity of $A$. unedo extracts is probably due to the presence of reductones and may serve as an indicator of its potent antioxidant activity. The antioxidant effect of reductones is based on the destruction of the free radical chain by donating a hydrogen atom 32 . Polyphenols may act in a similar way as reductones react with free radicals to turns them into more stable products and abort free radical chain reactions ${ }^{36}$. It has been reported that the ability of flavonoids to reduce depend on the standard redox potential of the metal and flavonoid structure 37.

The inhibitory effects on lipid peroxidation and autoxidation of linoleic acid have been attributed to the radical scavenging activity 38. Both studied extracts inhibited the lipid peroxidation, probably by neutralizing free radicals formed in the system, and this ability could be attributed to their phenolic constituents that are potent antioxidants and inhibit strongly the lipid peroxidation 39, 40. Phenolic compounds are electron donors that can quench and neutralize free radicals or decompose peroxides ${ }^{41}$. The antioxidant ability is related to the structural characteristics of the antioxidant agents and also to their ability to interact with and penetrate the lipid bilayer ${ }^{42}$. Also, it has been reported that the structure and the lipophilicity of antioxidant compounds are determinant factors of their antioxidant properties, most probably affecting the depth of incorporation of a compound in the lipid phase of membrane 43. The non-polar antioxidants are concentrated within the lipid-water interface, preventing so radical formation of $\beta$ carotene and lipid oxidation. While, polar antioxidants are diluted in the aqueous phase, therefore, its ability to inhibit lipids peroxidation is lower than that of non-polar antioxidants 28 .

Erythrocytes are susceptible to oxidation; this is why it has been used as a cellular model to investigate oxidative damage in biomembranes. These cells are considered as the first target for free radicals attacks due to the presence of two important and potent promoters of reactive oxygen species, which are: high membrane concentration of polyunsaturated fatty acids and $\mathrm{O}_{2}$ transport associated with redox-active hemoglobin molecule 44 . Free radicals or oxidants are known to cause structural damage to erythrocyte membranes, by oxidation of lipid and protein composed 45 . AAPH is one of the peroxyl radical initiators that generates free radicals by its thermal decomposition and causes therefore hemolysis 19,46 .

The ability of $A$. unedo extracts to delay hemolysis might be attributed to its phenolic and flavonoids contents. Indeed, previous studies have reported that polyphenols and flavonoids can protect erythrocytes from free radicalinduced oxidative hemolysis and increase their resistance to damage caused by oxidants $47,48,49,50$. These studies are in agreement with those of 51 and 52, showing that flavonoids can penetrate in the lipid bilayers of erythrocytes and linked to the plasma membrane and thus inhibit the peroxidation of lipid and enhances the integrity of red blood cells against hemolysis.

\section{CONCLUSION}

On the basis of the overhead results, it can be concluded that the extracts of Arbutus unedo exhibit a good antioxidant activity. This activity may be due to phytochemical constituents present in these extracts. The amount of phenolic compounds in the extracts plays a significant role in their antioxidant capacity, and it can be concluded that ethyl acetate proved to be the best solvent for the extraction of the plant material. Furthermore, it can be concluded that these extracts can be used as a potent natural antioxidant source in the preparation of various herbal medicines for the prevention and/or treatment of oxidative stress-related diseases.

\section{Conflict of Interest}

Authors declare no conflict of interest.

\section{Funding}

This work was supported by the Algerian Ministry of Higher Education and Scientific Research (MESRS) [grant number CNEPRU/D01N01UN190120150001 Project].

\section{REFERENCES}

[1]: Inbathamizh L, Ponnu TM, Mary EJ, "In vitro evaluation of antioxidant and anticancer potential of Morinda pubescens synthesized silver nanoparticles", J. Pharm. Re. 2013; 6:32-38. 
[2]: Lobo V, Patil A, Phatak A, Chandra N, "Free radicals, antioxidants and functional foods: impact on human health", Pharmacogn Rev. 2010; 4:118-126.

[3]: Gönenç A, Hacışevki A, Tavil Y, Çengel A, Torun M, "Oxidative stress in patients with essential hypertension: a comparison of dippers and nondippers", Eur J Intern Med. 2013; 24: 139-144.

[4]: Ramana KV, Srivastava S, Singhal SS, "Lipid peroxidation products in human death and disease", Oxid Med Longev. 2013; 2013:1-3

[5]: Ozsoy N, Can A, Yanardag R, Akev N, "Antioxidant activity of Smilax excelsa L. leaf extracts", Food Chem. 2008; 110: 571-583.

[6]: Rice-Evans C, Miller N, Paganga G, "Antioxidant properties of phenolic compounds", Trends Plant Sci. 1997; 2(4):152-159.

[7]: El Haouari M, L'opez JA, Mekhfia H, Rosado JJ, Salido GM, "Antiaggregant effects of Arbutus unedo extracts in human platelets", J. Ethnopharmacol. 2007; 113:325-331

[8]: Ziyyat A, Legssyer A, Mekhfi A, Dassouli A, Serhrouchni M, Benjelloun J, "Phytotherapy of hypertension and diabetes in oriental Morocco", J. Ethnopharmacol. 1997; 58:45-54.

[9]: Çubukçu B, Suzgeç S, Geleneksel Folklorik Droglar Dergisi, 1997; $4: 4$.

[10]: Pallauf K, Rivas-Gonzalo JC, del Castillo MD, Cano MP, de Pascual-Teresa S, "Characterization of the antioxidant composition of strawberry tree (Arbutus unedo L.) fruits", J. Food Compos. Anal. 2008; 21:273-281.

[11]: Benahmed M, Djeddi N, Akkal S, Laouar H, "Saccocalyx satureioides as corrosion inhibitor for carbon steel in acid solution", Int J Ind Chem. 2016; 7:109-120

[12]: Li HB, Cheng KW, Wong CC, Fan KW, Chen F, Jiang Y, "Evaluation of antioxidant capacity and total phenolic content of different fractions of selected microalgae", Food Chem. 2007; 102:771-776.

[13]: Bahorun T, Gressier B, Trotin F, Brunete C, Dine T, Vasseur J, Gazin JC, Pinkas M, Luycky M, Gazin M, "Oxygen species scavenging activity of phenolic extracts from hawthorn fresh plant organs and pharmaceutical preparations", Arzneimittelforschung.1996; 46: 1086-1089.

[14]: Que F, Mao L, Pan X, "Antioxidant activities of five Chinese rice wines and the involvement of phenolic compounds", Food Res Int. 2006; 39:581-587.

[15]: Sudha G, Sangeetha Priya M, Indhu Shree R, Vadivukkarasi S, "In vitro free radical scavenging activity of raw pepino fruit (solanum muricatum aiton) ", Int. J. Curr. Pharm. Res. 2011; 3:137-140.

[16]: Lee DS, Woo JY, Ahn CB, Je JY, "Chitosan-hydroxycinnamic acid conjugates: Preparation, antioxidant and antimicrobial activity", Food Chem. 2014; 148:97-104

[17]: Rohit Y, Saurabh R, Ajay S, "Review on antioxidants activity and its evaluation". J. Pharma. Res. 2012; 1(2):41-58.

[18]: Bougatef A, Hajji M, Balti R, Lassoued I, Triki-Ellouz Y, Nasri M, "Antioxidant and free radical-scavenging activities of smooth hound (Mustelus mustelus) muscle protein hydrolysates obtained by gastrointestinal proteases", Food Chem. 2009; 114: 1198-1205.

[19]: Bouhlali EDT, Alem C, Filali Zegzouti Y, "Antioxidant and antihemolytic activities of phenolic constituents of sixmoroccan date fruit (Phoenix dactylifera L.) syrups", Biotechnol. Indian J. 2016; 12(1): 45-52.

[20]: Pabuçcuoğlu A, Kıvcak B, Bas M, Mert T, "Antioxidant activity of Arbutus unedo leaves", Fitoterapia. 2003; 74: 597-599.

[21]: Jiang YH, Jiang XL, Wang P, Hu XK, "In vitro antioxidant activities of water-soluble polysaccharides extracted from isaria farinosa b05", J. Food. Biochem. 2005; 29:323-335.

[22]: Nagulendran KR, Velavan S, Mahesh R, Hazeena Begum V, "In Vitro antioxidant activity and total polyphenolic content of Cyperus rotundus Rhizomes", E-J. Chem. 2007; 4:440-449.

[23]: Serhat K, Sait C, Semra T, Ökkes Y and Ismail T, "Hydrogen Peroxide Radical Scavenging and Total Antioxidant Activity of Hawthorn", Chem. J. 2012; 02:9-12.

[24]: Gülçin 'I, Alici HA, Cesur M, "Determination of in Vitro Antioxidant and Radical Scavenging Activities of Propofol", Chem. Pharm. Bull. 2005; 53(3):281-285

[25]: Yin H, Xu L, Porter NA, 2011. "Free radical lipid peroxidation: mechanisms and analysis", Chem Rev. 2011; 111:5944-5972.

[26]: Gonçalves S, Gomes D, Costa P, Romano A, "The phenolic content and antioxidant activity of infusions from Mediterranean medicinal plants". Ind Crops Prod. 2013; 43:465471.
[27]: Ben Jeddou K, Chaari F, Maktouf S, Nouri-Ellouz O, Helbert CB, Ghorbel RE, "Structural, functional, and antioxidant properties of water-soluble polysaccharides from potatoes peels", Food chem. 2016; 205: 97-105.

[28]: Balti R, Bougatef A, El Hadj Ali N, Ktari N, Jellouli K, NedjarArroume N, Dhulster P, Nasri M, "Comparative Study on Biochemical Properties and Antioxidative Activity of Cuttlefish (Sepia Officinalis) Protein Hydrolysates Produced by Alcalase and Bacillus licheniformis NH1 Proteases", J. Amino Acids, 2011; 2011: 1-11.

[29]: Zhao H, Zhang H, Yang S, "Phenolic compounds and its antioxidant activities in ethanolic extracts from seven cultivars of Chinese jujube" Food Sci. Hum. Wellness. 2014; 3:183-190.

[30]: Gülçin İ, Beydemir Ş, "Phenolic compounds as antioxidants carbonic anhydrase isoenzymes inhibitors" Mini-Rev. Med. Chem. 2013; 13:408-430.

[31]: Carcache-Blanco EJ, Cuendet M, Park EJ, Su BN, Rivero-Cruz JF, Farnsworth NR, Pezzuto JM, Douglas Kinghorn A, "Potential cancer chemopreventive agents from Arbutus unedo", Nat. Prod. Res. 2006; 20:327-334.

[32]: Prasad KN, Xie H, Hao J, Yang B, Qiu S, Wei X, Chen F, Jiang Y, "Antioxidant and anticancer activities of 8-hydroxypsoralen isolated from wampee [Clausena lansium (Lour.) Skeels] peel", Food Chem. 2010; 118:62-66.

[33]: Gülçin İ, Bursal E, Şehitoğlu HM, Bilsel M, Gören AC, "Polyphenol contents and antioxidant activity of lyophilized aqueous extract of propolis from Erzurum", Food Chem. Toxicol. 2010; 48:2227-2238.

[34]: Priyadharshini SD, Sujatha V, "Antioxidant assessment for various solvent fractions of Cassia fistula Linn. flowers", Int. J. PharmTech Res. 2012; 4(1):510-517.

[35]: Soobrattee MA, Neergheen VS, Luximon-Ramma A, Aruoma OI Bahorun T, "Phenolics as potential antioxidant therapeutic agents: mechanism and actions", Mutat. Res. 2005; 579:200-213.

[36]: Kosanic M, Rankovic B, Dasic M, "Antioxidant and antimicrobial properties of mushrooms", Bulg. J. Agric. Sci. 2013; 19(5):10421048.

[37]: Mira L, Fernandez MT, Santos M, Rocha R, Florencio $\mathrm{MH}$, Jennings KR, "Interactions of flavonoids with iron and copper ions: a mechanism for their antioxidant activity", Free Radic. Res. 2002; 36:1199-208.

[38]: Bajpa VK, Sharma A, Kang SC, Baek KH, "Antioxidant, lipid peroxidation inhibition and free radical scavenging efficacy of a diterpenoid compound sugiol isolated from Metasequoia glyptostroboides", Asian Pac. J. Trop. Med. 2014; 7: 9-15.

[39]: Lizcano AL], Viloria-Bernal M, Vicente F, Berrueta LA, Gallo B, Martınez-Ca namero M, Ruiz-Larrea MB, Ruiz-Sanz JI, "Lipid oxidation inhibitory effects and phenolic composition of aqueous extracts from medicinal plants of Colombian", Int J Mol Sci. 2012; 13:5454-5467.

[40]: Saleh MR, Hasan MH, Adam A, "Phenolic compound and antioxidant levels of Prismatomeris rajnglabra", J . Pharmacogn. Phytochem. 2015; 3:5-11.

[41]: Moyo B, Oyedemi S, Masika PJ, Muchenje V, "Polyphenolic content and antioxidant properties of Moringa oleifera leaf extracts and enzymatic activity of liver from goats supplemented with Moringa oleifera leaves/ sunflower seed cake", Meat Sci. 2012; 91:441-447.

[42]: Salcedo CL, Frías MA, Cutro AC, Nazareno MA, Disalvo EA, "Antiradical activity of gallic acid included in lipid interphases", BBA-Biomembranes, 2014; 1838: 2656-2661.

[43]: Djeridane A, Yousfi M, Brunel JM, Stocker P, "Isolation and characterization of a new steroid derivative as a powerful antioxidant from Cleome arabica in screening the in vitro antioxidant capacity of 18 Algerian medicinal plants", Food Chem.Toxicol. 2010; 48:2599-606.

[44]: Varghese CP, Ambrose C, Jin SC, Lim YJ, Keisaban T, "Antioxidant and anti-inflammatory activity of Eurycoma longifolia Jack, a traditional medicinal plant in Malaysia", Int. J. Pharm. Sci. Nano. 2013; 5:1875-1878.

[45]: Yang HL, Chen SC, Chang NW, Chang JM, Lee ML, Tsai PC, Fu $\mathrm{HH}$, Kao WW, Chiang HC, Wang HH, Hseu YC, "Protection from oxidative damage using Bidens pilosa extracts in normal human erythrocytes", Food Chem. Toxicol. 2006; 44:1513-21.

[46]: Yang HL, Korivi M, Lin MK, Chang HC-W, Wu C-R, Lee M-S, Chen WT-L, Hseu Y-H, "Antihemolytic and antioxidant properties of pearl powder against 2,2'-azobis(2-amidinopropane) dihydrochloride-induced hemolysis and oxidative damage to 
erythrocyte membrane lipids and proteins", J. Food drug anal. 2017; 25:898-907.

[47]: Yu J, Ahmednaand M, Goktepe I, "Effects of processing methods and extraction solvents on concentration and antioxidant activity of peanut skin phenolics", Food Chem. 2005; 90:199206.

[48]: Dai F, Miao Q, Zhou B, Yang L, Liu ZL, "Protective effects of flavonols and their glycosides against free radical-induced oxidative hemolysis of red blood cells", Life Sci. 2006; 78:248893.

[49]: Chaudhuri S, Banerjee A, Basu K, Sengupta B, Sengupta PK, "Interaction of flavonoids with red blood cell membrane lipids and proteins: antioxidant and antihemolytic effects", Int. J. Biol. Macromol. 2007; 41(1):42-48.
[50]: De Freitas MV, Rita de Cassia MN, da Costa Huss JC, de Souza TMT, Costa JO, Firmino CB, Penha-Silva N, "Influence of aqueous crude extracts of medicinal plants on the osmotic stability of human erythrocytes", Toxicol. In Vitro, 2008; 22: 219-224.

[51]: Alvarez-Suarez JM, Giampieri F, Gonzalez-Paramas AM, Damiani E, Astolfi P, Martinez-Sanchez G, Bompadre S, Quiles JL, Santos-Buelga C, Battino M, "Phenolics from monofloral honeys protect human erythrocyte membranes against oxidative damage". Food Chem Toxicol. 2012; 50: 1508-16.

[52]: Henneberg R, Otuki FM, Furman AEF, Hermann P, Nascimento AG, Leonart MSS, "Protective effect of flavonoids against reactive oxygen species production in sickle cell anemia patients treated with hydroxyurea", Rev. Bras. Hematol. Hemoter. 2013; 3:52-5. 